\title{
Modification of life history and morphometric traits of montane species as an expression of adaptive abilities to different climatic conditions - a case study of Petasites kablikianus Tausch ex Bercht. (the Babia Góra Mt, Western Carpathians, Poland)
}

\author{
Aldona Katarzyna Uziębło* \\ Department of Ecology, University of Silesia in Katowice, Jagiellońska 28, 40-032 Katowice, Poland
}

\begin{abstract}
Detailed data on the response of plants to different climatic conditions could gain insight into the early impacts of climate change upon functioning ecosystems especially alpine ones, the most specialized. Petasites kablikianus (Asteraceae) is a species with montane and disjunctive distribution range, and it is one of the best objects to such investigations. In Polish high mountains, it is represented the best on the northern slopes of the Babia Góra massif (the Babiogórski National Park) and it occurs in two, independent zones: subalpine (landslides, rock rubbles) and lower montane zone (gravels on stream banks). The climatic differences between these two zones result in a morphological differentiation of specimens but mainly in differences in the dynamics of the life history of both populations. Detailed phenological observations and biometrical measurements were made on five plots on both gynodynamic and androdynamic shoots in their natural environment and after transplantation. The most important result is a fact that the subalpine population is completely phenologically isolated. Moreover the differences in the dates of beginning vegetation and in the duration and dynamics of particular stages of development and in morphological structure of individuals between the upper and lower populations were also stated. The results show that the adaptability of the species present a great potential to respond to the possible effects of global warming by modifying the life history and extending of distribution range for low-lying areas.
\end{abstract}

Keywords: Petasites kablikianus; life history; phenological data; stages of development; subalpine species; global warming

\section{Introduction}

Biotic responses to climate change will likely be one of the most important ecology issues in the coming decades. Alpine plants specialized to extreme conditions are particularly sensitive to changes in factors like lengthening of vegetation season, precipitation, or temperature and it makes them good predictors of phenological response patterns [1].

Petasites kablikianus (glabrous butterbur) is a species with a typical montane and disjunctive distribution range. It occurs in the Southern Carpathians, the Dinar Alps and the Pirin Mts, in the Eastern and the Western Carpathians, and in the Giant Mts [2]. There are evidences that this is a species of high mountain origin, which is during the expansion on low-lying areas [3]. Glabrous butterbur is a

\footnotetext{
* Email: aldona.uzieblo@us.edu.pl
}

Handling Editor: Aleksandra Samecka-Cymerman rhizome geophyte and a clonal plant with an iterative type of growth. Characteristic to the species are: $(i)$ functional dioecism (gynodynamic specimens have biologically active pistillate flowers and androdynamic ones have active staminate flowers) [2,3], (ii) proanthia (blooming before foliation), and (iii) the beginning of vegetation as the very first species (frequently at the time when the snow cover begins to thaw). Petasites kablikianus has a discontinuous distribution in mountains; it occurs in two, independent zones: $(\boldsymbol{i})$ subalpine (screes, rock rubbles) and (ii) lower montane zone (gravels on stream banks and landslides) [3]. This kind of distribution is observed the best on the northern slopes of the isolated from other high mountains, massif of the Babia Góra Mt (the Babiogórski National Park and Reserve of Biosphere UNESCO). The climatic differences between these two zones result in a morphological differentiation of specimens [4] but mainly in differences in the dynamics of the life history of both populations. Phenological observations and biometric measurements 
of both, subalpine and lower montane zone populations, give the best image of differences of the course of shoot development in one season and show adaptive potential of the species. This study is an attempt to answer the following specific questions:

(i) are there differences in blooming and in growth of shoots and leaves between gyno- and androdynamic specimens from both altitudinal zones and what are the consequences of them?

(ii) are there differences between subalpine and low montane gynodynamic shoots in the course of processes of blooming, fructification, and seed dispersal?

(iii) are there such differences between specimens from one plot before and after transplantation?

and following general questions:

(i) what traits of life history plants and morphometric features change in reaction on climatic changes?

(ii) how alpine plants can adapt to climate warming?

Many authors point to the need for increased research on a detailed course of the life cycle of plants in a changing climate conditions, because many of phenological studies are based only on the dates of beginning of growing or florescence $[5,6]$. In order to meet such expectation the aim of this paper was to estimate the qualitative and quantitative differences in phenological and morphometric traits of life history between populations originating from the two altitudinal zones, to predict the possible effects of climatic changes on subalpine plant populations. An additional element of this work is to present a proven methods of phenological observations of plants of Asteraceae.

\section{Material and methods}

Because of its very long period of vegetation (butterbur specimens appear as almost the first plants at the time when the snow begins to thaw and remain until the assimilation leaves decay at the end of the vegetation season), detailed phenological observations were limited to the phenology of generative shoots in a single year. However, the dates of the fullness of fruiting phase, which had been observed in period of 22 years, were used for comparison.

\section{Study sites}

The specimens from four plots, located in the foothills and on the northern slopes of the Babia Góra Mt (the Żywiecki Beskid Mts, Western Carpathians), were studied in detail:

(i) plot I (600 $\mathrm{m}$ a.s.l.) - gravels on the stream-bank

(ii) plot II (745 m a.s.l.) - gravels on the stream-bank

(iii) plot III (1440 $\mathrm{m}$ a.s.l.) - shielded slope with an inclination of $30^{\circ}$

(iv) plot IV (1580 $\mathrm{m}$ a.s.l.) - slope with an inclination of $50^{\circ}$ exposed to the influence of atmospheric factors.

In the case of the upper zone, terminal plots (the highest and the lowest locations) were used in the research, while in the lower zone, the main criteria were the similarity of light conditions and the differences in the height (about $140 \mathrm{~m}$ between the plots studied in both zones). All plots are patches of the Petasitetum kablikiani Wal. 1933 association [7].

\section{Plant material}

In total 100 individuals (generative shoots) were analyzed, which included 79 gynodynamic (about 20 per plot) and 21 androdynamic shoots (10 and 11 per plot). One plot represented mixed population ("female" and "male" specimens in the same patch) in both zones and the other one was uniform, formed only by gynodynamic individuals.

\section{Phenological observations}

Detailed observations were made during the 1994 vegetation season. The following phenophases were counted as phenological characteristics:

(i) the appearance of flower buds - inflorescence extended from scaly stem leaves - FBd

(ii) the beginning of blooming - half-opened phyllaries of the calathid and the appearance of the tops of particular flowers - BB

(iii) the fullness of blooming - in the case of androdynamic specimens, calathids with $50 \%$ of blooming flowers were classified as this phenophase, and in the case of gynodynamic individuals, the blooming of a central staminate flower were taken into account, because of the difficulties with estimating the blooming stage of pistillate flowers - FB

(iv) withering - 50\% of withered flowers in androdynamic individuals and the decay of the central flower in gynodynamic individuals - $\mathrm{W}$

(v) fructification - this concerns only the gynodynamic specimens; over $50 \%$ of ripe cypselas - F

(vi) the beginning of dispersal - completely opened phyllaries of the calathid and the loss of single seeds - BD

(vii) the fullness of dispersal - 50\% of dispersed seeds) - FD

(viii) the end of dispersal - a few seeds in calathid or a lack of them - ED.

The observations were carried out in 5-7 days periods from March to the beginning of August 1994. The first observations were made at the moment when the entire inflorescence was clearly extended among the leaf scales (height of the shoot about $8 \mathrm{~cm}$ ). However, the real beginning of vegetation was 1-2 weeks before the first observation accounted for in the further analysis.

Mean month temperatures were measured in meteorological stations of the Institute of Meteorology and Water Management in Zawoja village (700 $\mathrm{m}$ a.s.l.) and the Markowe Szczawiny glade (1180 m a.s.l.).

\section{Morphological measurements}

During phenological observations the height of shoots and leaves were measured on each individual studied, marked at the beginning of the study period. The measurements of the leaves were repeated at the end of season in September in order to obtain their maximum height.

In preparatory observations (1992-1993), before the appropriate phenological studies, during the fullness of fructification biometrical measurements were made when the shoots had reached their maximum height and the leaves were 
completely developed. The dates of these measurements were used for the comparison analysis. Subsequent observations of the phenophase were made in 1998, 2009, and in 2014.

\section{Data analysis}

In the analysis of the results obtained, the absolute beginning and end of each phenophase on particular plots, its duration and intensity were examined. Because of the fact that a single shoot represents a few phenophases simultaneously, each day of measurements the percentage of calathids in the phenophase on the entire plot were shown in phenodiagrams. The maximum number of calathids for all of the individuals studied on each plot was treated as $100 \%$. Natural withering of the heads during the observations caused some losses (shown in the phenodiagrams).

In statistical data analysis all phenophases mentioned above were used as measurement levels of two main phenophases - blooming ( $\mathrm{FBd}, \mathrm{BB}, \mathrm{FB}, \mathrm{W})$ and fructification (F, BD, FD, ED) - compare the subchapter "Phenological observations". Statistical significance of differences in mean number of calathids in the phenophase between the plots studied and types of shoots were counted using ANOVA with repeated measurements (4 levels of repeated measurements in two main phenophases blooming and fructification) with 3 intergroup factors - plot (number of plot / altitudinal zone), sex (gynodynamic and androdynamic shoots), and week (week of observations). The analyses were made using the Statistica package version 9.0 (StatSoft 2010).

\section{Transplantation experiment}

In spring 1994, 20 blooming gynodynamic shoots with a few centimeters of rhizomes and leaf buds were collected from plots I and III. The material was taken and planted on both banks of the Wilczy Potok stream (600 m a.s.l., the Silesian Beskid Mts, Western Carpathians) on the same day. All of the seedlings began vegetation. Phenological observations were begun two years later, after the acclimatization of the transplanted plants (in 1996). In the first season after transplantation (1995); only all subalpine individuals bloomed and increased their number of shoots from 10 to 23 and to 36 in following year (1996). All of them were taken into account in further analysis as individuals from "plot T".

\section{Results}

Gynodynamic specimens from the lower montane zone underwent vegetation in a similar time frame (Tab. 1), though specimens from the lowest plot underwent the subsequent phases with a greater intensity, which meant that a larger part of the population simultaneously represented particular stages of each phenophase. On the second plot in this zone, specimens stayed in the phase of full blooming longer and reached the phase of full dispersal gradually (Fig. 1a,b). The natural loss of calathids amounted to about $10 \%$ on plot I and $18 \%$ on plot II.

In the subalpine zone, the beginning of vegetation in 1994 of both types of specimens was shifted by nine to ten weeks in relation to the lower zone. Gynodynamic specimens from the highest plot were distinguished by a greater intensity of blooming (Fig. 1c,d). The total time of fructification and dispersal of seeds was shorter (22 days; Tab. 1) and more intensive on this plot (Fig. 1c,d). This plot was also characterized by the smallest percentage of loss of buds (about $3 \%$ ). The most damage to calathids was observed on plot III $-31 \%$ (Fig. 1c).

In the case of the androdynamic specimens, they began their vegetation two weeks after the end of the blooming shoots of this type in the lower montane zone and two, or even three weeks, in the case of the lowest plot, after the end of the blooming gynodynamic shoots. Therefore, individuals of both zones are in absolute phenological isolation. The duration of the blooming of the subalpine specimens was almost two weeks shorter in comparison with individuals from the lower montane zone (Tab. 1), thus the following stages of blooming were more intensive as well. In particular, the appearance of buds in half the time is distinctive for this zone (Fig. 2a,b).

The results of preliminary observations of the transplanted specimens proved that they maintained the same time of blooming in relation to the home plot, but the duration of fructification was only half as long and extended about one week into the time of seed dispersal (Tab. 1). However, they became like specimens from plot I, which was located at the same altitude, in respect to the duration of particular phenophases (Fig. 3).

Tab. 1 Comparison of the duration of particular phenophases on the plots studied.

\begin{tabular}{|c|c|c|c|c|c|}
\hline No. of plot & $\begin{array}{l}\text { Altitudinal } \\
\text { zone }\end{array}$ & $\begin{array}{c}\text { Type of } \\
\text { individual }\end{array}$ & $\begin{array}{l}\text { Blooming } \\
\text { (days) }\end{array}$ & Fruiting (days) & Dispersal (days) \\
\hline I & Lower montane & Gynodynamic & 37 & 26 & 36 \\
\hline I & Lower montane & Androdynamic & 41 & - & - \\
\hline II & Lower montane & Gynodynamic & 44 & 29 & 36 \\
\hline III & Subalpine & Gynodynamic & 36 & 34 & 30 \\
\hline IV & Subalpine & Gynodynamic & 36 & 22 & 22 \\
\hline IV & Subalpine & Androdynamic & 29 & - & - \\
\hline Transplantation & Lower montane & Gynodynamic & 36 & 15 & 36 \\
\hline
\end{tabular}



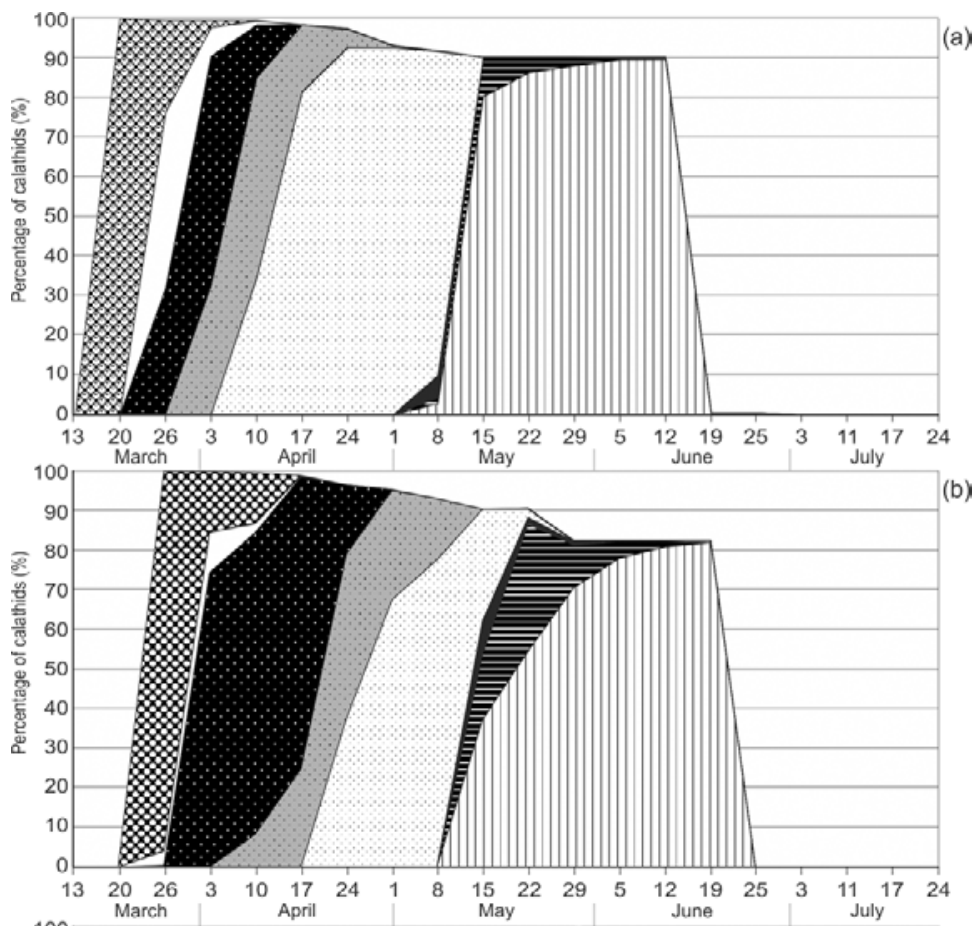

(b)
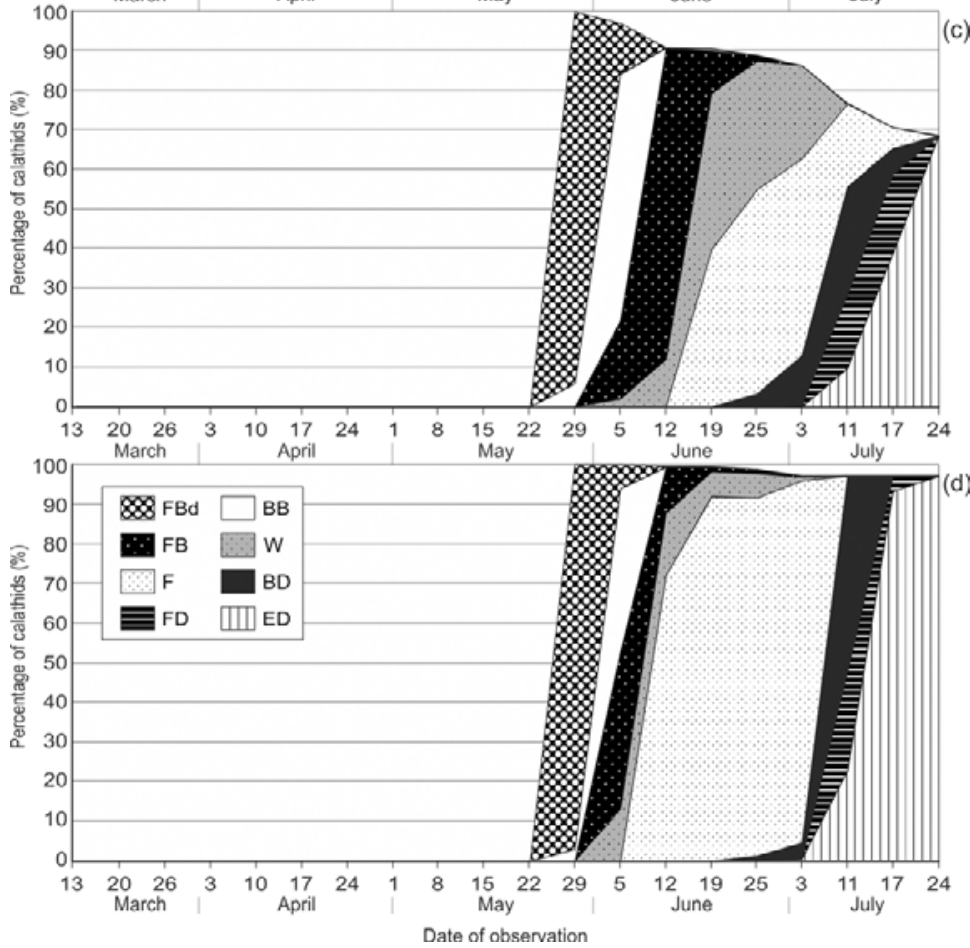

Fig. 1 A course of vegetation of gynodynamic shoots on plot I (a), II (b) in the lower zone and on plot III (c) and IV (d) in the subalpine zone: FBd - appearance of flower buds, BB - beginning of blooming, FB - fullness of blooming, $\mathrm{W}$ - withering, $\mathrm{F}$ - fructification, $\mathrm{BD}$ - beginning of dispersion, FD - fullness of dispersion, ED - the end of seed dispersion. A percentage of calathids represented particular phenophases of all shoots studied was used.

Because of the technical difficulties in carrying out detailed phenological observations over a long period of time, seasonal differences between the plots over a period of 22 years are shown in order to compare the dates of reaching the fructification phase by most specimens on the plot (Tab. 2).
The differences between particular seasons on each plot amounts about three weeks. In spite of this, the difference between the plots in one zone is consistently one week. In the subalpine zone the difference is similar, though a little shorter (five days on average), but in spite of the $140 \mathrm{~m}$ 

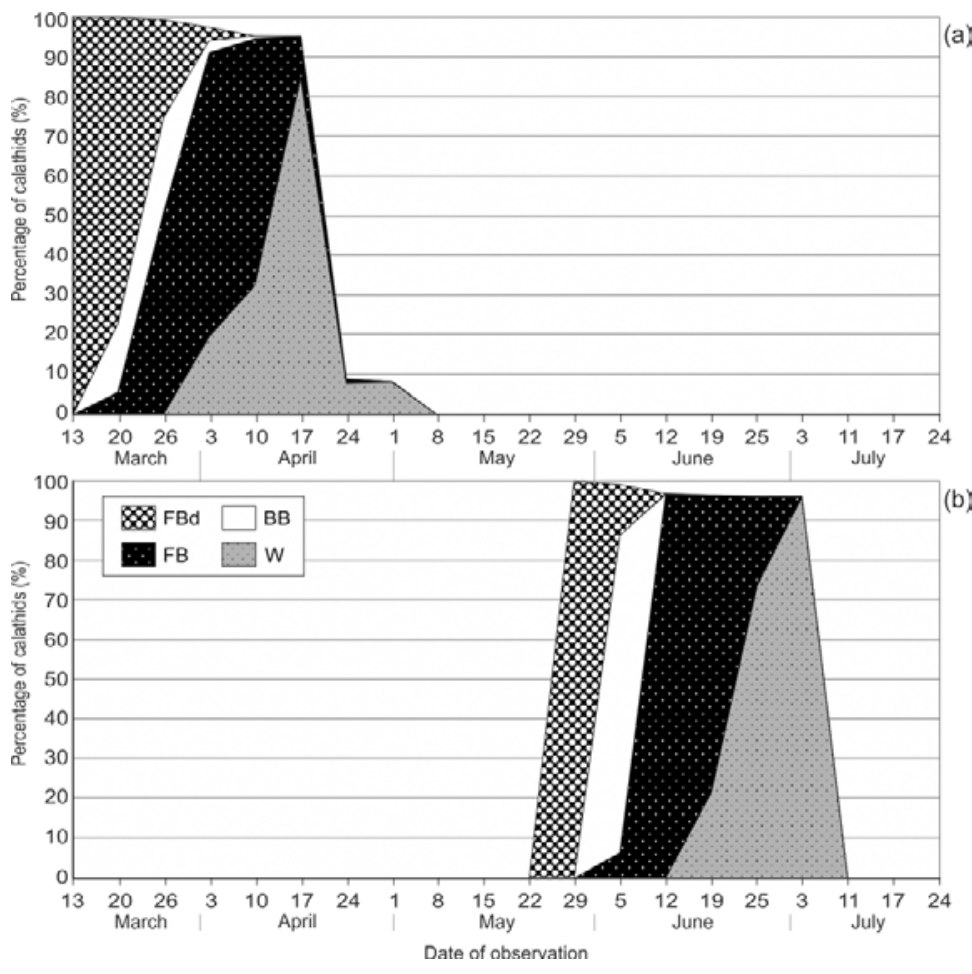

Fig. 2 A course of vegetation of androdynamic shoots on plot I (a) in the lower zone and IV (b) in the subalpine zone: FBd - appearance of flower buds, BB beginning of blooming, $\mathrm{FB}$ - fullness of blooming, $\mathrm{W}$ - withering. A percentage of calathids represented particular phenophases of all shoots studied was used.

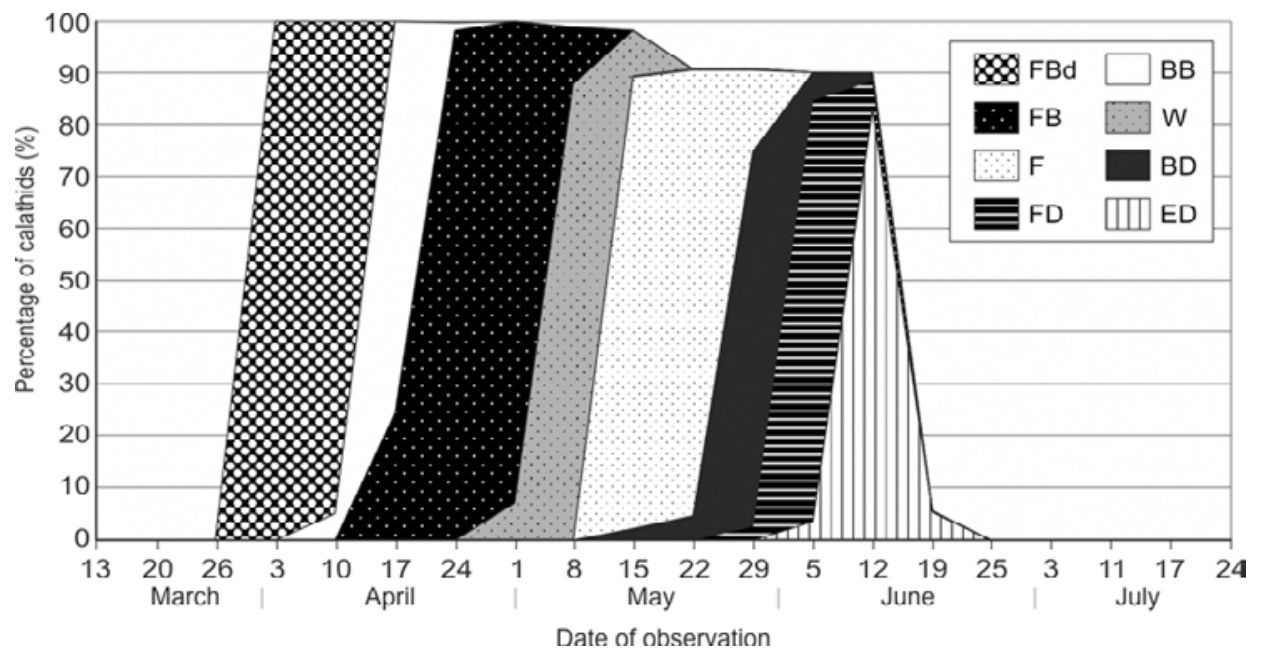

Fig. 3 A course of vegetation of gynodynamic shoots after transplantation (subalpine individuals; plot T). A percentage of calathids represented particular phenophases of all shoots studied was used.

difference in altitude, the fructification phase was reached earlier by specimens on the plot that was located higher. A distinct difference in the dates of full fructification was found between both examined populations of P. kablikianus (one to two months), but a constant shortening of this time was observed over the period of 22 years (Fig. 4).
Analysis of variance (ANOVA) proved that there are statistically significant differences of blooming intensity between gyno- and androdynamic shoots in subalpine zone (Fig. 5). The same analysis of mean number of calathids in particular phenophases revealed statistically significant differences especially distinct in blooming and fructification 
Tab. 2 Comparison of the dates of reaching the phase of fructification by Petasites kablikianus individuals on the plots studied.

\begin{tabular}{|c|c|c|c|c|c|c|c|c|c|c|c|c|c|}
\hline \multirow{2}{*}{$\begin{array}{l}\text { No. of } \\
\text { plot }\end{array}$} & \multirow{2}{*}{$\begin{array}{l}\text { Altitude } \\
\text { a.s.l. (m) }\end{array}$} & \multicolumn{2}{|c|}{1992} & \multicolumn{2}{|c|}{1993} & \multicolumn{2}{|c|}{1994} & \multicolumn{2}{|c|}{1998} & \multicolumn{2}{|c|}{2009} & \multicolumn{2}{|c|}{2014} \\
\hline & & \multicolumn{12}{|c|}{ Day of observation / Mean month temperature in zone $\left({ }^{\circ} \mathrm{C}\right)$} \\
\hline I & 600 & 8 May & \multirow{2}{*}{10.5} & $26 \mathrm{Apr}$ & \multirow{2}{*}{6.3} & 1 May & \multirow{2}{*}{10.6} & 15 May & \multirow{2}{*}{10.7} & 9 May & \multirow{2}{*}{11.3} & 2 May & \multirow{2}{*}{11.8} \\
\hline II & 745 & 11 May & & 5 May & & 8 May & & 20 May & & 12 May & & 7 May & \\
\hline III & 1440 & 9 Jun & \multirow{2}{*}{14.2} & 15 Jun & \multirow{2}{*}{13.1} & 25 Jun & \multirow{2}{*}{13.2} & 22 Jun & \multirow{2}{*}{15.3} & 10 Jun & \multirow{2}{*}{13.4} & 6 Jun & \multirow{2}{*}{14.7} \\
\hline IV & 1580 & 3 Jun & & 12 Jun & & 19 Jun & & 17 Jun & & 6 Jun & & 3 Jun & \\
\hline
\end{tabular}

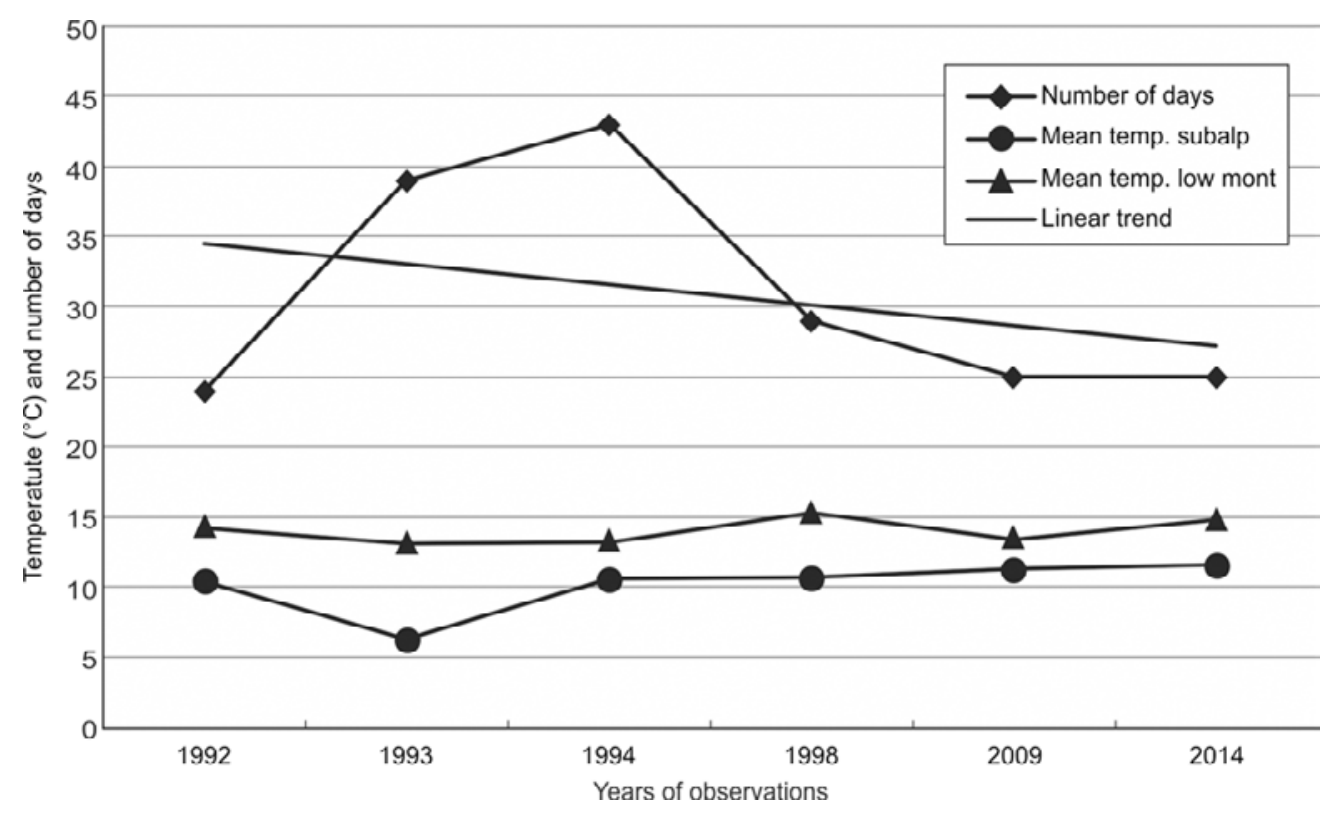

Fig. 4 Variation in time of the beginning of fructification of P. kablikianus individuals in two zones (the number of days between the dates of fructification from plots where plants begin the phenophase the latest in lower zone and the earliest in subalpine one) and in mean temperature in given month.

between both altitudinal zones (Fig. 6a,b). After transplantation shoots originating from subalpine plot III reveal statistically significant differences of mean number of calathids in particular phenophases in relation both, to subalpine and lower montane groups of individuals. Means of transplanted individuals are located between them. However it is worth noting that distribution of the means are similar to lower montane zone (characteristic peak in fullness of blooming FB; Fig. 6a). Statistical significance of particular options of analysis was confirmed by multivariant tests (Tab. 3).

In addition to the phenological observations, the mean maximum heights of generative shoots and leaves of both types of specimens from the four plots were compared. It turned out that plot I (the lowest location) was distinguished by the tallest shoots and leaves for the gynodynamic specimens and smaller height of the androdynamic specimens in comparison to the subalpine plots (Tab. 4). Distinct differences were found in the case of the mean maximum height of leaves as well. The leaves of both types of specimens from the lower zone are twice as tall as the leaves from the subalpine populations (Tab. 4). The dimensions of the subalpine specimens increased after their transplantation.

Moreover, it must be added that the gynodynamic specimens in the lower zone reached the maximum height of a shoot in the seventh week of development, and in the upper one in the sixth to seventh on plot III and in the fifth on plot IV. The androdynamic individuals from the lower zone finished the shoot growing phase in the fourth week, and in the subalpine zone they stop growing after three weeks.

To summarize, it should be pointed out that the differences in the dates of beginning vegetation between the upper and lower populations amounted five to seven weeks. In the lower montane zone, the gynodynamic specimens started blooming one week later than the androdynamic specimens. Such dependence was not observed in the subalpine zone. Differences both in the dynamics of the phenological changes in the P. kablikianus populations between both zones (about one to two weeks) and statistically significant differences in intensity of blooming were found. The entire development cycle from buds to the end of seed dispersal 

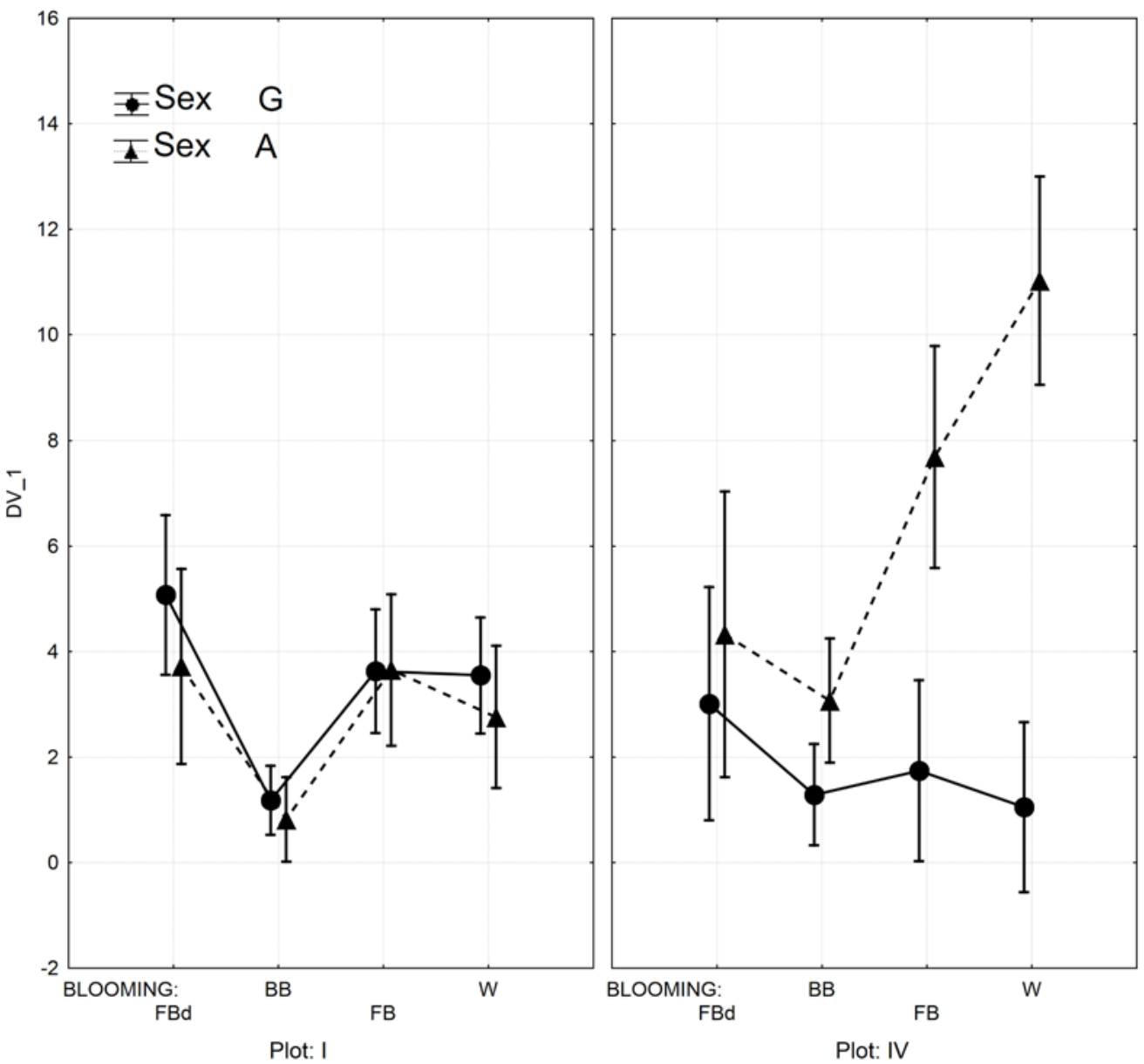

Fig. 5 The differences of mean number of calathids in particular phenopases of blooming between androdynamic and gynodynamic shoots from both altitudinal zones (plot I - lower montane zone; plot IV - subalpine zone) at $95 \%$ confidence intervals: $F(3,1638)=5.5118, P=0.00091$.

took about $14-16$ weeks in the lower zone and nine weeks in the upper zone. In the case of subalpine specimens after transplantation, it lasted 13 weeks. In the lower zone, the vegetation of "male" specimens took eight weeks and in the subalpine zone - seven weeks.

\section{Discussion}

The occurrence of Petasites kablikianus with the same vitality in two different altitudinal (climatic) zones may be an evidence of its abilities to adapt for very various climate conditions. The differences in its life history between these two altitudinal belts, besides morphological differentiation $[3,4]$ and significant shift in the dates of the beginning of growth are based mainly on dynamics and intensity of particular phenophases. Subalpine population, which is phenologically isolated, faster and more intensively passes through the entire vegetation cycle. The differences are connected with phenotypic plasticity. Changes in dynamics in life cycle of individuals after transplantation confirm that. The morphometric features, especially the ratio between height of shoots and leaves are less typical for alpine plants. In most cases, plants reveal a tendency to become dwarfed with an increase in altitude above sea level. This dependence in the case of the species studied is related only to leaf height but not to generative shoots. The largest maximum height of the gynodynamic shoots was noted on the lowest located plot, where the development cycle was also the longest. However, it is interesting that the height of these shoots on the other plots is different to a lesser degree, in spite of a two-week difference in the duration of that cycle. In the lower elevation the shoot height and leaf length ratio amounts to almost one, in the upper zone it is about two (for both plots in the zone). This may indicate on the adaptation of the subalpine population to a shorter vegetation season. The glabrous butterbur inflorescences that grow twice over the leaf layer ensure a more effective dispersal of seeds for themselves. It could also be proved by that the androdynamic specimens did not reveal this dependence. However, the results obtained from a comparison of the shoot height of androdynamic specimens are interesting as well. The subalpine individuals are about twice as tall, although their life cycle is two weeks shorter than the androdynamic shoots from the lowest located plot. It could also be the adaptation to high mountain conditions. A high altitude above sea level may limit the number of potential pollinators. Large, attractive flowers or a mixed pollination - such as anemophily or self-fertile 

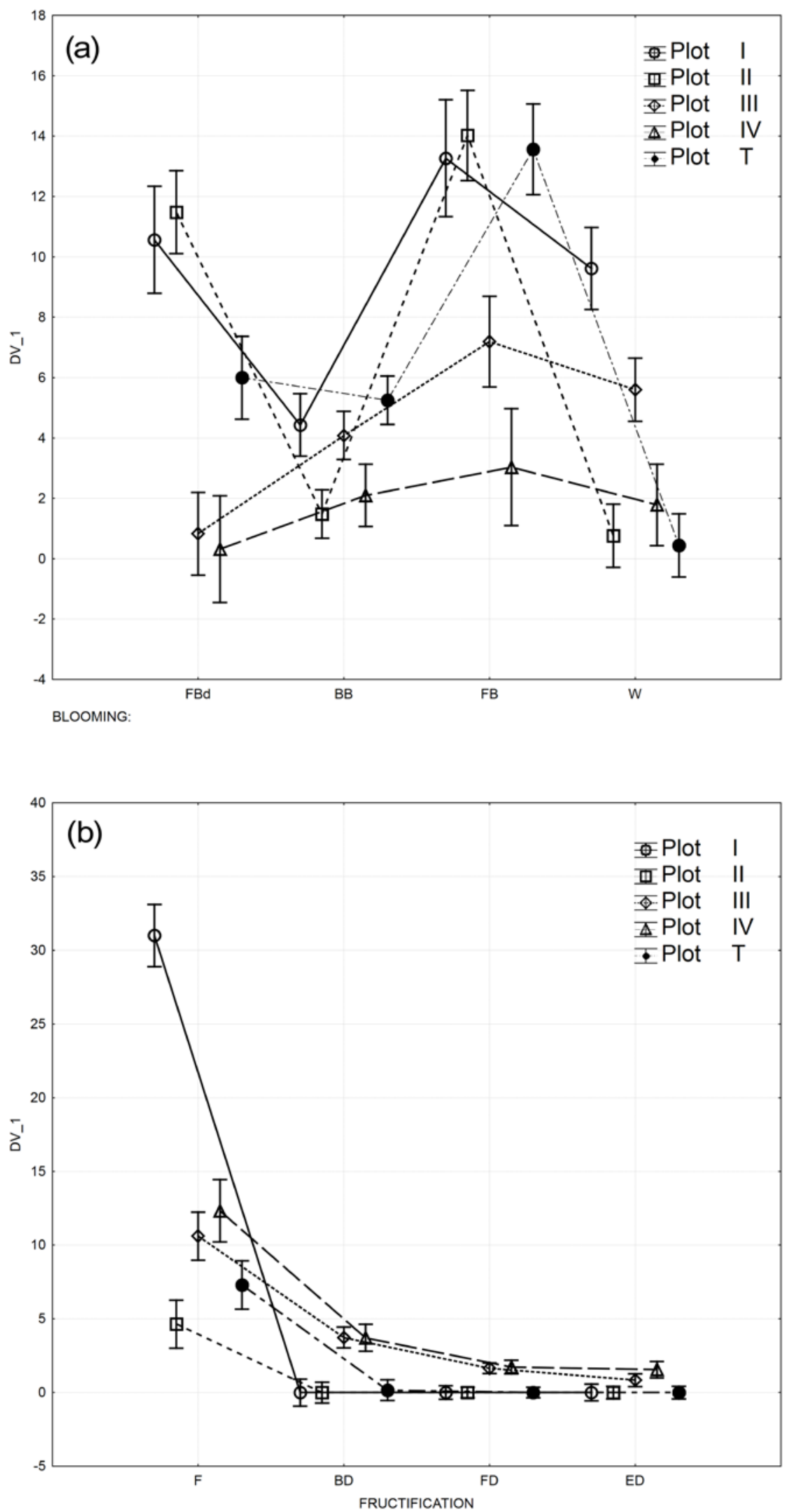

Fig. 6 a The differences of mean number of calathids in particular phenopases of blooming of gynodynamic shoots from both altitudinal zones (plots I, II - lower montane zone; plots III, IV - subalpine zone) and after transplantation (plot T) at $95 \%$ confidence intervals: $F(12,1200)$ $=25.283, P=0.0000$. $\mathbf{b}$ The differences of mean number of calathids in particular phenopases of fructification (with dispersal of seeds process) of gynodynamic shoots from both altitudinal zones (plots I, II - lower montane zone; plots III, IV - subalpine zone) and after transplantation $($ plot $\mathrm{T})$ at $95 \%$ confidence intervals: $F(12,900)=78.728, P=0.000$. 
Tab. 3 Results of multivariant tests in ANOVA with repeated measurements; all results are statistically significant.

\begin{tabular}{|c|c|c|c|}
\hline Test & Value & $F$ & $P$ \\
\hline \multicolumn{4}{|c|}{ Blooming $\times$ Plot $\times$ Sex (Fig. 5 ) } \\
\hline Wilks' & 0.856931 & 15.2486 & 0.000000 \\
\hline Pillai's & 0.143069 & 15.2486 & 0.000000 \\
\hline Hotelling's & 0.166955 & 15.2486 & 0.000000 \\
\hline Roy's & 0.166955 & 15.2486 & 0.000000 \\
\hline \multicolumn{4}{|c|}{ Blooming $\times$ Plot (Fig. 6a) } \\
\hline Wilks' & 0.468522 & 29.1273 & 0.000000 \\
\hline Pillai's & 0.615727 & 25.8245 & 0.000000 \\
\hline Hotelling's & 0.957182 & 31.6402 & 0.000000 \\
\hline Roy's & 0.719732 & 71.9732 & 0.000000 \\
\hline \multicolumn{4}{|c|}{ Fructification $\times$ Plot $($ Fig. 6b) } \\
\hline Wilks' & 0.387191 & 28.3522 & 0.000000 \\
\hline Pillai's & 0.664048 & 21.3205 & 0.000000 \\
\hline Hotelling's & 1.450924 & 35.8701 & 0.000000 \\
\hline Roy's & 1.354331 & 101.5748 & 0.000000 \\
\hline
\end{tabular}

are the mechanisms that are most frequently used by high mountain plants $[8,9]$. Proanthia (characteristic to Petasites genus) is treated as an adaptation to a high mountain climate as well. Dafni et al. [10] proved this fact on the example of the Crocus and Colchicum genera. However, not all plants are subject to that scheme [11]. In the case of Petasites kablikianus, the lengthening of the blooming period by unequal entrance into particular phenophases (on one shoot several phenophases are represented simultaneously; calathides from the lower part of inflorescence ripen the earliest and from the top - the latest) and elevation of inflorescences over a layer of leaves in alpine population could be this kind of adaptation as well. Another kind of that adaptation could also be the fact that glabrous butterbur distinctly overtakes other species occurring in the zone at the beginning the vegetation season. That is connected with practical lack of competition for pollinators, and their presence is main factor in seed production and reproductive success [12].
Petasites kablikianus is a plant with a wide ecological spectrum, though it is specialized to colonize specific habitats that are characterized by good light conditions and high moisture in loose, stony soil [3]. This is why it is able to grow in the lower montane zone on the gravels of stream banks and on slopes that have been strongly modeled by geomorphological processes in the subalpine zone (on analyzed area it reveals discontinuity - it does not occur on transitional stands). There are a few evidences that the species uses this opportunity to broaden its mountain range and it is also possible that other alpine species can react in this way on climate warming [3], however rather opposite direction of plant migration due to climate warming was stated [13].

Another aspect of these phenological observations is the prediction of the effect of climatic changes. Twenty two years of study of both $P$. kablikianus populations have revealed changes in the time it takes to reach particular stages of development (Tab. 2) and a tendency to a shortening of the time between beginnings of particular vegetation stages was found (Fig. 4). However, the stable influence of local climatic and habitat conditions on the dates of the beginning of vegetation was observed. In every year that was analyzed, on the lower located subalpine plot III (1440 m a.s.l.), the vegetation season began later and the scheme of vegetation is different than on the upper plot IV (1580 $\mathrm{m}$ a.s.l.), which is more exposed to such factors as: insolation, wind, speed of snow thawing and surface flow (a larger inclination). The distinct influence of local conditions on the quality of the vegetation and reproduction of high mountain plants have been proven by the results of studies carried out in the United States in the Rocky Mts [14], in the mountains of Scandinavia [15-17] or in Japan on Hokkaido in the Taisetsu Mts $[18,19]$. It was found that the effect of global warming will mostly influence the survival, growth, biomass production and reproduction activity of these subalpine plants which occur on places where snow cover is disappearing the most quickly [12,20-22]. However, the results of these investigations also proved that the most natural damage to inflorescences (31\%), which is directly connected with the reproduction processes, were noted exactly on the plot that is isolated from wind and low temperature influence and by long laying snow cover the longest.

Summarizing, these studies showed:

(i) distinct differences in the duration and dynamics of particular stages of development and in morphometric

Tab. 4 Comparison of the mean max. height of the shoots and leaves of both types of individuals, in both altitudinal zones.

\begin{tabular}{|c|c|c|c|c|c|c|c|c|c|}
\hline \multirow{3}{*}{$\begin{array}{l}\begin{array}{l}\text { No. of } \\
\text { plot }\end{array} \\
\text { I }\end{array}$} & \multicolumn{3}{|c|}{ Generative shoots } & \multicolumn{6}{|c|}{ Leaves* } \\
\hline & \multirow{2}{*}{\multicolumn{2}{|c|}{$\begin{array}{c}\text { gynodynamic }(\mathbf{c m} \pm S D) \\
91.7 \pm 20\end{array}$}} & \multirow{2}{*}{$\begin{array}{c}\text { androdynamic }(\mathrm{cm} \pm S D) \\
27.0 \pm 13\end{array}$} & \multicolumn{4}{|c|}{ gynodynamic $(\mathrm{cm} \pm S D)$} & \multicolumn{2}{|c|}{ androdynamic $(\mathrm{cm} \pm S D)$} \\
\hline & & & & \multicolumn{2}{|c|}{$75.4 \pm 11$} & \multicolumn{2}{|c|}{$102.6 \pm 18$} & $28.0 \pm 5$ & $103.8 \pm 16$ \\
\hline II & \multicolumn{2}{|c|}{$68.4 \pm 12$} & - & \multicolumn{2}{|c|}{$61.7 \pm 7$} & \multicolumn{2}{|c|}{$78.7 \pm 8$} & - & - \\
\hline III & $76.2 \pm 13$ & $91.9 \pm 11^{* *}$ & - & $36.9 \pm 7$ & $53 \pm 16$ & $70.6 \pm 13$ & $104.3 \pm 9$ & - & - \\
\hline IV & \multicolumn{2}{|c|}{$68.1 \pm 14$} & $41.4 \pm 9$ & \multicolumn{2}{|c|}{$33.4 \pm 9$} & \multicolumn{2}{|c|}{$58.0 \pm 9$} & $40.1 \pm 10$ & $62.2 \pm 12$ \\
\hline
\end{tabular}

* The first number is the measurement made at the end of seed dispersal and concerns the first leaf. The second number is the measurement made on the second leaf at the end of the vegetation period (September). ${ }^{*}$ Measurements of specimens after transplantation. 
parameters of both subalpine and low montane populations

(ii) adaptive abilities of the species connected with a high degree of phenotypic plasticity what indicates a great potential of montane species in reacting to the possible effects of global warming by, i.e., changing of life history and spreading on low-lying areas

\section{Acknowledgments}

I thank the late Prof. Jerzy Wołek for taking the time to help me at statistical analyses, Mrs Maryla Palowska for her help in preparing final version of figures and Mrs Michele Simmons for proofing English version of the text. I also would like to thank reviewers for their detailed, valuable and very helpful remarks. The studies were funded by the University of Silesia as statutory research.

\section{Competing interests}

No competing interests have been declared.

\section{References}

1. Smith JG, Sconiers W, Spasojevic MJ, Ashton IW, Suding KN. Phenological changes in alpine plants in response to increased snowpack, temperature and nitrogen. Arct Antarct Alp Res. 2012;44:135-142. http://dx.doi.org/10.1657/1938-4246-44.1.135

2. Toman J, Starý F. Über die Verbreitung der Art Petasites kablikianus. Preslia. 1966;38:168-185.

3. Uziębło AK. Petasites kablikianus Tausch ex Berchtold as a pioneer species and its abilities to colonise initial habitats. Katowice: Wydawnictwo Uniwersytetu Śląskiego; 2011. (Prace Naukowe Uniwersytetu Śląskiego w Katowicach; vol 2886).

4. Uziębło AK. Subalpine populations of Petasites kablikianus Tausch ex. Bercht. in the Babia Góra and the Karkonosze National Parks. Opera Corcontica. 2004;41:135-141.

5. Wolkovich E, Ettinger AK. Back to the future to the plant phenology research. New Phytol. 2014;203:1021-1024. http://dx.doi.org/10.1111/ nph.12957

6. Körner C, Basler D. Phenology under global warming. Science. 2010;327:1461-1462. http://dx.doi.org/10.1126/science.1186473

7. Matuszkiewicz W. Przewodnik do oznaczania zbiorowisk roślinnych Polski. Warszawa: Wydawnictwo Naukowe PWN; 2008.

8. Herrera CM. Seasonal variation quality of fruits and diffuse coevolution between plant and avian disperser. Ecology. 1982;63:773-775. http://dx.doi.org/10.2307/1936798

9. Dafni A. Mediterranean autumn-winter pollination adaptations. Bocconea. 1996;5:171-182.

10. Dafni A, Shmida A, Avishai M. Leafless autumn-flowering geophytes in the mediterranean region - phytogeographical, ecological and evolutionary aspects. Plant Syst Evol. 1981;137:181-193. http://dx.doi. org/10.1007/BF00989872

11. Schwartz-Tzachor R, Eisikowitch D, Dafni A. Flower characteristics (iii) a clear phenological isolation of subalpine population of P. kablikianus from the Babia Góra Mt, which can have serious genetic consequences

(iv) a clear reduction of time between the start of one of the phenophases (fructification) in the populations of the lower and upper zone of $P$. kalikianus distribution.

and breeding system of two phenological ecotypes of Cyclamen persicum Mill. (Myrsinaceae) in Israel. Plant Syst Evol. 2008;274:127-134. http://dx.doi.org/10.1007/s00606-008-0027-x

12. Kameyama Y, Kudo G. Intrinsic and extrinsic factors acting on the reproductive process in alpine snow-bed plants: roles of phenology, biological interaction, and breeding system. Plant Species Biol. 2015;30:3-15. http://dx.doi.org/10.1111/1442-1984.12070

13. Erschbamer B, Kiebacher T, Mallaun M, Unterluggauer P. Shortterm signals of climate change along an altitudinal gradient in the South Alps. Plant Ecol. 2009;202:79-89. http://dx.doi.org/10.1007/ s11258-008-9556-1

14. Galen C, Stanton ML. Concequences of emergence phenology for reproductive success in Ranunculus adoneus (Ranunculaceae). Am J Bot. 1991;78:978-988. http://dx.doi.org/10.2307/2445177

15. Stenström M, Molau U. Reproductive ecology of Saxifraga oppositifolia: phenology, mating system, and reproductive success. Arct Antarct Alp Res. 1992;24:337-343. http://dx.doi.org/10.2307/1551289

16. Totland Q. Influence of climate, time of day and season, and flower density on insect flower visitation in Alpine Norway. Arct Antarct Alp Res. 1994;26:66-71. http://dx.doi.org/10.2307/1551879

17. Totland Q. Limitations on reproduction in alpine Ranunculus acris. Can J Bot. 1997;75:137-144. http://dx.doi.org/10.1139/b97-016

18. Kudo G, Suzuki S. Relationships between flowering phenology and fruit-set of dwarf shrubs in alpine fellfield in northern Japan: a comparison with subarctic heathland in northern Sweden. Arct Antarct Alp Res. 2002;34:185-190. http://dx.doi.org/10.2307/1552470

19. Kudo G, Hirao AS. Habitat-specific responses in the flowering phenology and seed set of alpine plants to climate variation: implications for global-change impacts. Popul Ecol. 2006;48:49-58. http://dx.doi. org/10.1007/s10144-005-0242-Z

20. Molau U. Climatic impacts on flowering, growth, and vigour in an arctic-alpine cushion plant, Diapensia lapponica, under different snow cover regimes. Ecol Bull. 1996;45:210-219.

21. Inouye DW, Morales MA, Dodge GJ. Variation in timing and abundance of flowering by Delphinium barbeyi Huth (Ranunculaceae), the roles of snowpack, frost, and La Niña, in the context of climate change. Oecologia. 2002;130:543-550. http://dx.doi.org/10.1007/ s00442-001-0835-y

22. Saavedra F, Inouye DW, Price MV, Harte J. Changes in flowering and abundance of Delphinium nuttalianum (Ranunculaceae) in response to a subalpine climate warming experiment. Glob Chang Biol. 2003;9:885-894. http://dx.doi.org/10.1046/j.1365-2486.2003.00635.x 